\title{
Design of Strategy to Increase the Added Value and Competitiveness of Products Mini Cocoa Processing Industry Based OVOP with using Interpretive Structural Modeling
} (ISM)

\author{
Lamatinulu $^{1, *}$, Pratikto ${ }^{2}$, Purnomo Budi Santoso ${ }^{2}$, Sugiono $^{2}$ \\ ${ }^{1}$ Departement of Industrial Engineering, Faculty of Industrial Technology, Moslem University of Indonesia, Makassar 90324, Indonesia \\ ${ }^{2}$ Department of Industrial Engineering, Faculty of Engineering, University of Brawijaya, Malang 65145, Indonesia
}

Received 25 April 2017; Accepted 20 September 2017

\begin{abstract}
Increasing added value and competitive- ness of small and medium industries processing cocoa in Indonesia is still low, so it needs a development strategy model mini cocoa processing industry.T he condition is a major concern in the central areas of cocoa production in the area Palopo, Luwu, Sulawesi Selatan Province as the largest cocoa producer in Indonesia. In this matter, the purpose of this study was to develop a strategic model of variable structure-based design with the integration of One Village One Product (OVOP) basic principles and cooperatives as an important strategy to increase value-added and competitiveness of product locally mini-industry cocoa processing. The identification process and variable definition for the development strategy based on the study of literature, interviews and a survey using a questionnaire instrument to explore the opinions of experts. The method used is the Interpretive Structural Modeling (ISM) to design a model structuring the level of strategy in the development of a mini cocoa industry.The conclusion of this research found that to improve the competitiveness of local products of cocoa on the global market needed a key strategy in the form of the availability, appropriateness, and quality of a raw material of cocoa beans, innovation and diversification of products based on the quality, support of technology and implementation modern marketing system.
\end{abstract}

Keywords: OVOP, ISM, Cocoa, Strategy, Competitiveness

\section{Introduction}

In Indonesia cocoa is a commodity that plays quite an important role in the national economy, which has been able to contribute foreign exchange of USD 1,053,446,947 through exports of processed cocoa products and cocoa beans [1]. According to statistics from the agricultural organization in the world in 2011 Indonesia is the second largest cocoa seed producer in the world, that can be described as follows; Ivory Coast $33.8 \%(1,559,441$ metric tonnes), Indonesia $15.4 \%$ (712 200 metric tons), Ghana $15.2 \%$, equivalent to 700020 metric tons [2]. Cocoa crop plantation area in the Indonesia \pm 1.8529 million hectares with the production of cocoa beans around 740.510 tons per year and an average productivity of $400 \mathrm{~kg}$ per ha. The largest cocoa producer in Indonesia, according to statistics in 2013 was the province of Sulawesi Selatan amounted 146.840 tons [3]. Especially Palopo Luwu Raya region is the largest area of cocoa production in Sulawesi Selatan [4].

The above description demonstrates the potential for production and development opportunities chocolate industry actually very big on areas in Sulawesi Selatan in particular areas in the Luwu Raya. However, in reality, the growth and development of the cocoa processing industry into refined products such as cocoa liquor, cocoa cake, cocoa butter, and cocoa powder is still low, So it is still dominated for the export in the form of low-quality seed, so that it becomes one of the causes low value added and

*E-mail address: lamatinulu@gmail.com

ISSN: $1791-2377 @ 2017$ Eastern Macedonia and Thrace Institute of Technology. All rights reserved. doi:10.25103/iestr.105.12 competitiveness of processed cocoa products. As a result of Indonesian cocoa products are exported in the form of seed quality and low price could potentially eliminate the estimated profit of 150 million dollars, or 1.4 trillion rupiahs per year [5]. These facts prove that the cocoa industries sector in Indonesia is still weak, so it takes the industry able to diversify products to provide value added [6].

Based on the potential of cocoa production in South Sulawesi, then push some areas in the region to develop the cocoa processing industry small and medium scale based One Village One Product (OVOP). This is the right step because agricultural commodities can be the leading sector for OVOP movement is very appropriate to be applied in Indonesia [7]. OVOP is applied to three basic principles which include; local but global, self-reliance and creativity, and human resources development [8].The basic principle is meaningful ability to create a local product that is acceptable globally, exploiting the potential of creatively with an independent business, and the potential development of society [9].

In one area in Indonesia that is Palopo town has been developed small and medium industry cocoa processing based of OVOP cooperatives as economic development policy. But in this case, the OVOP program industry has not demonstrated a significant impact on the increase in value added, competitiveness of processed cocoa products. This is due to the absence of a clear understanding of the implementation of the basic principles of the philosophy of OVOP local but global, as the findings of Claymone [10] which asserts that the failure of OVOP program in Indonesia because it is not based on the understanding of the philosophy and strategy implementation. To realize the basic 
principle of local but global cocoa processing industries based mini OVOP, it is necessary to have a strategy to increase the added value and competitiveness of products. This is very important because the OVOP based industry can have an impact on people's income increase of farmers if supported by a strategy of innovation, application of technology, improved quality, increased value-added, and support for modern marketing system $[11,12]$.

Based on some description of the above-mentioned problems, the main purpose of this research is to develop a model design strategies for improving the added value and competitiveness of mini local cocoa processing industry based on OVOP that focuses on the basic principle of "local but global". Level model of strategies design through the identification and structuring ranking strategy, analyse the relationship between variables linkage strategy and developing a structural model using the approach Interpretative Structural Modelling (ISM).

\section{Literature Review}

One Village One Product (OVOP) plays an important role towards improving the performance and added value for small and medium industries by improving the quality, the application of technology [12]. Implementation of the basic principles of the program OVOP One District, One Product (ODOI) is critical for SMEs in the Malaysia [13] and the impact on the development of rural Agroindustri [14,](Pasaribu, 2011). OVOP approach is very appropriate for the potential development of the superior product area, especially in the design of new products of high added value $[10,15,16]$. The OVOP based role, then, OVOP could affect people's income increase [11], poverty alleviation, the promotion of creativity and the development of self-reliance [17].

OVOP based industries can have an impact on the public revenue enhancement through innovation, application of technology, improving the quality and added value is supported modern marketing $[11,12]$. Implementation of the basic principles of OVOP global yet local development strategy can be developed into a mini industrial establishment. To develop principles based industries, local produce globally competitive requires the formulation of a model structuration design strategy. The approach method that can be used for the development of the strategy is the Interpretative Structural Modeling (ISM).

ISM was first introduced by Warfield in 1973 to organize a complex problem [18]. ISM can be applied to summarize and identify the relationship between the variables strategy is developed that will be able to use ISM $[19,20]$. Basically, ISM can be used to identify the key variables and analyze the relationship between variables in an industry [21]. Designed the model of interpretation of the performance of small and medium industries [22]. The ISM process can clarify the definition of a model well to find the factors, or the elements of a strategy to solve the problem [23].

\section{Material and Method}

\subsection{The scope of the research}

This study is limited to the discussion of aspects of local products on the development of mini-power global cocoa processing industry based on OVOP. In this study focused on the discussion of designing the structuring element of a strategy to increase the added value and competitiveness of products with the development of mini cocoa industry OVOP, which is developing a strategy based on one of the basic principles of OVOP namely Local yet, but globally significant local products but can be accepted globally. Respondents are experts on cocoa agro-industry background academics and practitioners. Data were collected through the study of literature, interviews, discussions and brainstorming.

\subsection{Stages of implementation of the ISM}

Stages of research methodology undertaken in the implementation of the ISM method, refer to the steps of logical steps that have been developed by Warfield and Anukul [18, 24], which can be described as follows:

1. Stages identification of elements of a strategy relevant to the problems through the study of literature and expert opinion that is considered a good knowledge of the problems the cocoa processing industry.

2. Stage building contextual relationships among elements for the purpose of modelling.

3. Phase preparation of a single structured interaction matrix (Structural Self-Interaction Matrix / SSIM). Matrix aims to represent the respondent's perception of the relationship element target element. The type of the relationship between the two elements of the system is examined using four symbols that can be described as follows:

$V$ : shows the relationship of the elements $E_{i}$ to $E_{j}$, and not vice versa

A: shows the relationship of the elements $E_{j}$ to $E_{i}$, and not vice versa

$X$ : show the interrelation relationship between $E_{i}$ and $E_{j}$, and vice versa

$O$ : show indicates that $E_{i}$ and $E_{j}$ unrelated

4. Phase preparation Reachability Matrix (Reachability Matrix-RM): $A_{n} R M$ prepared then change the symbols SSIM into a binary matrix. SSIM conversion to RM using the following rules:

If the relationship $E_{i}$ to $E_{j}=V$ in SSIM the elements $E_{i j}=$ 1 and $\mathrm{E}_{\mathrm{ji}}=0$

If the relationship $E_{i}$ to $E=A$ in SSIM the elements $E_{i j}=$ 0 and $\mathrm{E}_{\mathrm{ji}}=1$

If the relationship $E_{i}$ to $E_{j}=X$ in SSIM the elements $E_{i j}=$ 1 and $\mathrm{E}_{\mathrm{ji}}=1$

5. Stage classification strategy elements into four parts; autonomous, dependents, linkage and independent

6. Classify the elements in the different levels of the structure of the ISM is done through the participation rate. At this stage the two devices in associating with each element $E_{i}$ of the system. Reachability set $\left(R_{i}\right)$ is a set of all elements that can be reached from the element $\mathrm{E}_{\mathrm{i}}$, and antecedent $\operatorname{Set}\left(\mathrm{A}_{\mathrm{i}}\right)$.

7. The preparation phase matrix Canonical through grouping elements within the same level in the development of a matrix that is used to prepare the preparation digraph.

8. Stage preparation digraph which is Directional Graph concept, which is a graph depicting the elements that are interconnected directly and levels of hierarchy.

9. Stage preparation of Interpretative Structural Model mini development strategy based OVOP cocoa processing industry and cooperatives. 


\section{Results}

\subsection{Variable element strategy formulation}

Through the study of literature and opinions of respondents experts, has identified as many as 11 elements of strategy formulation. Description of the strategy is an element of a strategy that has been formulated those through the assessment process in depth, in order to become a basic input for the determination of structuring elements of strategy. In broad outline the scope of value added element of strategy and competitiveness of products includes; aspects of the cocoa bean variety is superior availability, appropriateness aspects of the production process, the feasibility aspects of quality of raw materials and processed products, aspects of technology, standardization of production processes and product quality, and marketing systems. The formulation of the strategy that has been established to encourage an increase in the added value and competitiveness of products mini cocoa processing industry based One Village One Product (OVOP) as described in Table 1.

Table 1. Formulation of the strategy aspect of local produce cocoa globally competitive

\begin{tabular}{c|l}
\hline Code & \multicolumn{1}{c}{ Formulation of the strategy } \\
\hline P1 & Availability of land for cocoa plantation productive seed varieties owned by local farmers \\
P2 & Selection machines, processing tools and method especially tools and fermentation technology \\
P3 & Raw material availability and appropriateness quality of cocoa beans according to the standard quality \\
P4 & $\begin{array}{l}\text { Determination of the brand, the design aesthetic packaging, and taste the authenticity of local cocoa products } \\
\text { P5 }\end{array}$ \\
Peasibility of product quality through the implementation of GMP and Hazard Analysis and Critical Control \\
of the Point (HACCP)
\end{tabular}

\subsection{Structural Self - Interaction Matrix (SSIM)}

Preparation of SSIM based on expert opinion and understanding of agribusiness, cocoa processing industry. Expert opinion obtained through interviews, brainstorming in developing relations contextual relationship between the formulation of development strategies mini establishment of cocoa processing industry can be seen in table 2 .

Table 2. Structural Self-Interaction Matrix

\begin{tabular}{|c|c|c|c|c|c|c|c|c|c|c|c|}
\hline \multirow{2}{*}{$\begin{array}{l}\text { Element } \\
\text { to }\end{array}$} & \multicolumn{11}{|c|}{ Element to } \\
\hline & P11 & $\mathrm{P} 10$ & P9 & P8 & P7 & P6 & P5 & $\mathrm{P} 4$ & P3 & $\mathrm{P} 2$ & $\mathrm{P} 1$ \\
\hline P1 & $\mathrm{V}$ & $\mathrm{V}$ & $\mathrm{V}$ & $\mathrm{X}$ & $\mathrm{X}$ & $\mathrm{V}$ & $\mathrm{V}$ & $\mathrm{V}$ & $\mathrm{V}$ & $\mathrm{V}$ & \\
\hline $\mathrm{P} 2$ & V & V & A & A & A & A & A & A & A & & \\
\hline P3 & V & V & $\mathrm{V}$ & $\mathrm{X}$ & V & V & $\mathrm{V}$ & V & & & \\
\hline P4 & V & V & A & A & A & $X$ & X & & & & \\
\hline P5 & V & V & A & A & A & $X$ & & & & & \\
\hline P6 & V & V & $\mathrm{V}$ & A & A & & & & & & \\
\hline P7 & V & V & $\mathrm{V}$ & $X$ & & & & & & & \\
\hline P8 & V & V & $\mathrm{V}$ & & & & & & & & \\
\hline P9 & V & V & & & & & & & & & \\
\hline P10 & V & & & & & & & & & & \\
\hline
\end{tabular}

Based on contextual relationships in the SSIM then, developed into a matrix reachability. Reachability matrix values to be obtained through the transformation of the relationship contextual sub-element of strategy into a binary 0 and 1 , as shown in table 3 .

Table 3. Reachability matrix initial

\begin{tabular}{|c|c|c|c|c|c|c|c|c|c|c|c|}
\hline & P1 & P2 & P3 & P4 & P5 & P6 & P7 & P8 & P9 & $\mathrm{P} 10$ & P11 \\
\hline $\mathrm{P} 1$ & 1 & 1 & 1 & 1 & 1 & 1 & 1 & 1 & 1 & 1 & 1 \\
\hline P2 & 0 & 1 & 0 & 0 & 0 & 0 & 0 & 0 & 0 & 1 & 1 \\
\hline P3 & 0 & 1 & 1 & 1 & 1 & 1 & 1 & 1 & 1 & 1 & 1 \\
\hline P4 & 0 & 1 & 0 & 1 & 1 & 1 & 0 & 0 & 1 & 1 & 1 \\
\hline P5 & 0 & 1 & 0 & 1 & 1 & 1 & 0 & 0 & 1 & 1 & 1 \\
\hline P6 & 0 & 1 & 0 & 1 & 1 & 1 & 0 & 0 & 1 & 1 & 1 \\
\hline P7 & 1 & 1 & 0 & 1 & 1 & 1 & 1 & 1 & 1 & 1 & 1 \\
\hline P8 & 1 & 1 & 1 & 1 & 1 & 1 & 1 & 1 & 1 & 1 & 1 \\
\hline P9 & 0 & 1 & 0 & 1 & 1 & 0 & 0 & 0 & 1 & 1 & 1 \\
\hline P10 & 0 & 0 & 0 & 0 & 0 & 0 & 0 & 0 & 0 & 1 & 1 \\
\hline P11 & 0 & 0 & 0 & 0 & 0 & 0 & 0 & 0 & 0 & 1 & 1 \\
\hline
\end{tabular}


To obtain more accurate results than, be revised SSIM and transformation by performing analysis using the rules of Boolean operations that qualify reflexive and transitive.
Based on the results obtained revision, revision of the SSIM shown in Table 4.

Table 4. Reachability matrix final results and interpretation

\begin{tabular}{|c|c|c|c|c|c|c|c|c|c|c|c|c|c|}
\hline & $\mathrm{P} 1$ & $\mathrm{P} 2$ & P3 & P4 & P5 & P6 & P7 & P8 & P9 & $\mathrm{P} 10$ & P11 & $\begin{array}{l}\text { Driver } \\
\text { Power }\end{array}$ & Ranking \\
\hline P1 & 1 & 1 & 1 & 1 & 1 & 1 & 1 & 1 & 1 & 1 & 1 & 11 & 1 \\
\hline P2 & 0 & 1 & 0 & 0 & 0 & 0 & 0 & 0 & 0 & 1 & 1 & 3 & 4 \\
\hline P3 & 1 & 1 & 1 & 1 & 1 & 1 & 1 & 1 & 1 & 1 & 1 & 11 & 1 \\
\hline P4 & 0 & 1 & 0 & 1 & 1 & 1 & 0 & 0 & 1 & 1 & 1 & 7 & 2 \\
\hline P5 & 0 & 1 & 0 & 1 & 1 & 1 & 0 & 0 & 1 & 1 & 1 & 7 & 2 \\
\hline P6 & 0 & 1 & 0 & 1 & 1 & 1 & 0 & 0 & 1 & 1 & 1 & 7 & 2 \\
\hline P7 & 1 & 1 & 1 & 1 & 1 & 1 & 1 & 1 & 1 & 1 & 1 & 11 & 1 \\
\hline P8 & 1 & 1 & 1 & 1 & 1 & 1 & 1 & 1 & 1 & 1 & 1 & 11 & 1 \\
\hline P9 & 0 & 1 & 0 & 0 & 0 & 0 & 0 & 0 & 1 & 1 & 1 & 4 & 3 \\
\hline P10 & 0 & 0 & 0 & 0 & 0 & 0 & 0 & 0 & 0 & 1 & 1 & 2 & 5 \\
\hline P11 & 0 & 0 & 0 & 0 & 0 & 0 & 0 & 0 & 0 & 1 & 1 & 2 & 5 \\
\hline $\begin{array}{c}\text { Depen- } \\
\text { dence }\end{array}$ & 4 & 9 & 4 & 7 & 7 & 7 & 4 & 4 & 8 & 11 & 11 & & \\
\hline
\end{tabular}

Matrix reachability final partitioned on the basis based on a set of reachability and antecedents for each formulation of the strategy through a series of iterations that are grouped in various level, through a series of iterations, are grouped into various levels as outlined in table 5.

Table 5. Partitioning Reachability Matrix Based on 5 Iteration

\begin{tabular}{|c|c|c|c|c|}
\hline $\begin{array}{l}\text { Element } \\
\text { Strategy }\end{array}$ & Reachability & Antecedent & Intersection & Level \\
\hline$\overline{\mathrm{P} 10}$ & 10,11 & $1,2,3,4,5,6,7,8,9,10,11$ & 10,11 & 1 \\
\hline P11 & 10,11 & $1,2,3,4,5,6,7,8,9,10,11$ & 10,11 & 1 \\
\hline $\mathrm{P} 2$ & 2 & $1,2,3,4,5,6,7,8,9$ & 2 & 2 \\
\hline P9 & 9 & $1,3,4,5,6,7,8,9$ & 9 & 3 \\
\hline P4 & $4,5,6$ & $1,3,4,5,6,7,8$ & $4,5,6$ & 4 \\
\hline P5 & $4,5,6$ & $1,3,4,5,6,7,8$ & $4,5,6$ & 4 \\
\hline P6 & $4,5,6$ & $1,3,4,5,6,7,8$ & $4,5,6$ & 4 \\
\hline $\mathrm{P} 1$ & $1,3,7,8$ & $1,3,7,8$ & $1,3,7,8$ & 5 \\
\hline P3 & $1,3,7,8$ & $1,3,7,8$ & $1,3,7,8$ & 5 \\
\hline P7 & $1,3,7,8$ & $1,3,7,8$ & $1,3,7,8$ & 5 \\
\hline P8 & $1,3,7,8$ & $1,3,7,8$ & $1,3,7,8$ & 5 \\
\hline
\end{tabular}

Establishment of model base development Strategy ISM Based on the final reachability, structural model strategy elements can be produced in the form of graphs generated digraph. Grafik is called a digraph which explicitly describes grouping elements of a strategy to realize aspects of local products that can be globally competitive. The grouping of elements of the strategy is divided into three sectors, sector II could profoundly influence by elements of strategies other (Dependent), sector III meaningful relationships among elements of the strategy are not stable (Linkage) and sectors IV, which means a policy that is free and has a great driving force against other policies (Independent). No policies are currently in the first sector is not significantly associated with the system(Autonomous). Clearly, chart can digraph showed in Figure 1.

\section{Discussion}

In Figure 1 shows that the strategy of P2, P9, P10 and P11 are the strategies that are in sector II (independent). The independent strategies can be influenced by the other strategies. The strategy selection of methods, tools and machinery in the process the primer cocoa processing industry particularly in the fermentation process $(\mathrm{P} 1)$ is important because it is a determinant of the quality of cocoa beans, it is supported by the results of research that states that the selection of tools and methods of drying greatly impacted $[25,26]$. Especially the selection of methods on the cocoa beans quality and means of the fermentation process is part of a very important element, because of a direct impact on the taste, quality of cocoa beans and pasta products, fat and cocoa powder [27,28]. Strategy P9 regarding the application of the method of selecting machinery, equipment, type and flow processes and strategies P10 about marketing promotions processed cocoa products is also an important strategy, as argued by Ngungi [12] the application of appropriate technology and market availability greatly influence on the development of Small and Medium Enterprises based One Village One Product. 
Elements of the strategy are included in the sector III (Linkage) includes strategies P4, P5, and P6 (see Figure 1). This strategy is an of strategy the hook between sectors I and IV. The P4 strategy about the determination of the brand, packaging design to enhance competitiveness in the global market is an important strategy. It is supported by the results of studies that the brand strategy and product packaging have the significant impact on sales performance and affect consumer purchases [29,30]. The strategy P5 and P6 is a strategy that emphasizes at the feasibility of product quality through the application of Hazard Analysis and Critical Control of the Point (HACCP) and Good Manufacturing Process (GMP). This strategy is very important to improve the performance of cocoa industry mini, this matter supported research findings Suchanek [31] which state that the feasibility of the product by improving the quality of impact on industry performance and consumer satisfaction.

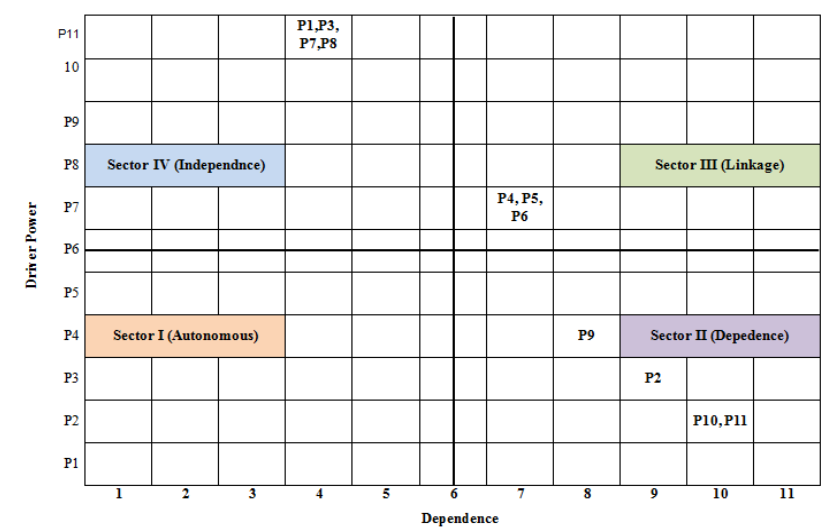

Fig. 1. Matrix driving force dependence strategy of supporting development OVOP mini cocoa industry

The strategy in the sector of IV is a strategy that will have a great driving force to realize the local products miniindustry cocoa that can be globally competitive. The elements included in the independent sector strategy includes a strategy P1, P3, P7, and P8. All elements of the strategy on the fourth sector is at the fifth level position as in Figure 1. This means that dependent strategy is a strategy that has a low dependence of and has a huge driving force to other strategies. Availability of land for cocoa plantation productive superior varieties owned by farmers (P1) is a very important strategic factor, because it can be a source of raw material cocoa seed supply, and can shorten the value chain and supply chain of cocoa beans. Diversification strategy and product innovation (P7) is the development and innovation of products to meet the tastes and needs of consumers. The implementation of this strategy it is important to increase sales, profits and flexibility through the creation of new products, as proposed by Fitriani et al. [32] that diversification of product may impact on increase sales volume, profitability, and flexibility. Innovation Strategy is important done through the implementation phases product development process is good, it is appropriate proposed by Monsef [33] that the stage of new product innovation need to go through the process, the planning, development, marketing, and commercialization. Related strategy of innovation, the development of mini industrial OVOP cocoa processing scale of SMEs need to be supported by a strategy of innovation in developing new products of value and competitiveness is high, it is supported by the findings Ibidunni et al. [34] who argued that in order to meet the demands and expectations consumer and SMEs market needs to do some research and product innovation.

\section{Conclusion}

Structuring the design of development strategies mini cocoa processing industry based basic principle of One Village One Product (OVOP) with ISM approach, can be applied in finding a key strategy of adding value and competitiveness of products. The main strategy to realize increased added value and competitiveness of the cocoa processing industry based on OVOP include; availability of cocoa seed varieties produced by local farmers as a source of raw materials, standardization of raw material quality cocoa beans are processed, product development through diversification and product innovation, selection of technology, machinery and equipment are appropriate, differentiation and quality of processed cocoa products, implementation of promotion system appropriate and modern marketing.

\section{Acknowledgements}

The author would like to thank the Ministry for Research, Technology and Higher Education on the scholarships that have been awarded to support these research activities. Thanks are also extended to the Moslem University Indonesia of on research funding that has been given.

Access article distributed under the terms of the Creative Commons Attribution Licence

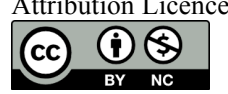

1. Ministry of Industry of the Republic of Indonesia, (2009). Cacao Industry Development Roadmap, the Directorate General of Agro and Chemical, Jakarta.

2. FAOSTAD (2013), The Top 5 Cocoa Bean Producing Countries, The Statistics Division Of Food and Agricultural Organisation.

3. BPS. 2014. Plantation crop production by province and type plant in Indonesia. Jakarta: Central Bureau of Statistics Republic of Indonesia.

4. South Sulawesi Plantation Office (2013). Broad, Production, Productivity, and Number of independent smallholders per commodity per district, South Sulawesi province.

5. Soim, Ahmad (2013), Improving the value-added cocoa, Tabloid Sinar Tani Build Independence Agribusiness.

6. Putri, S.A., Sutopo, W. Prihawantara, S., and Matheos D.C.R. (2015). Value Chain Improvement for Cocoa Industry in Indonesia by Input-Output Analysis. Proceedings of the International Multi Conference of Engineers and Computer Scientists Vol. 2, Honkong.

\section{ferences}

7. Savitri, D., "An approach of sustainable development: rural revitalization as the pioneer of OVOP movement", International Journal OVOP, 1 (7), 2008, pp.79-88.

8. Hiramatsu, M. (2007). The One Village, One Product movement spreading throughout the world. Presentation at the National Conference on "One Village, One Product" Movement. Cambodia: Asian Productivity Organization.

9. JAICAF (2008), One Village One Product Movement in Afrika, Japan Association for International Collaboration of Agriculture and Foresttry.

10. Claymone, Y. and Jaiborisudhi, W., "A study on one village one product project (OVOP) in Japan and Thailand as an alternative of community development in Indonesia", The International Journal of East Asian Studies, 16 (1), 2011, pp.51-60.

11. Chidumu, I., Juliana (2007), The Impact Of "One Village One Product (OVOP)" On Household Income - Implications On Food Security: The case of Bvumbwe operation area, Thyolo District, 
Malawi, A Thesis Submitted to the Graduate School in partial fulfillment for the requirementsof the Collaborative Master of Science Degree in Agricultural and Applied Economics(CMAAE) of Egerton University.

12. Ngugi J. N. and Bwisa, H., "Factors influencing growth of group owned small and medium enterprises: a case of One Village One product enterprises", International Journal of Education and Research, 1(8), 2013, pp.1-14.

13. Kader, A.Radiah, Mohammad, Bin, Rosli, M., "Success Factors for Small Rural Entrepreneurs under the OneDistrict-One-Industry Programme in Malaysia", Contemporary Management Research, 5 (2), 2009, pp. 147-162.

14. Pasaribu, M.S., "The development of rural agro-industries with the approach of One Village One Product (OVOP)", Forum Agro Ekonomi, 29(1), 2011, pp.1-11.

15. Hirohata, N., "One Village One Product movement in Laos", International Journal of Engineering Innovation and Management, 3(2):,2013, pp.31-35.

16. Triharini, M., Larasati D. and Susanto R., "Approach one village one product ( OVOP ) to expand their local craft: a case study craft pottery on in Plered, district Purwakarta", Journal of Visual Art and Design, 6(1),2014, pp.29-42.

17. Denpaiboon, Chaweewan, Amatasawatdee , K. (2012), Similarity and Difference of One Village One Product (OVOP) for Rural Development Strategy in Japan and Thailand, Japanese Studies Journal Special Issue : Regional Cooperation for Sustainable Future in Asia.

18. Warfield, J., "Social Systems: Planning, Policy and Complexity", John Wiley and Sons, Inc, New York, NY,1976.

19. Warfield, J.W., "Developing interconnected matrices in structural modeling", IEEE Transcript on Systems. Men and Cybernetics, 4(1), 1974, pp. 51-81.

20. Sage, A.P. (1977). Interpretive Structural Modeling: Methodology for Large-Scale Systems. New York, NY: McGraw-Hill.

21. Saxena J.P., Sushil and Vrat P., "The impact of indirect relationships in classification of variables: A MICMAC analysis for energy conservation", System Research, 7(4),1990, pp. 245-253.

22. Cagno, E., Micheli, G.J.L., Jacinto, C., Masi, D., "An interpretive model of occupational safety performance for Small- and Mediumsized Enterprises", International Journal of Industrial Ergonomics, 44, 2014, pp. 60-74.
23. Attri R.,Dev N., and Sharma V., "Interpretive Structural Modelling (ISM) approach: An Overview", Research Journal of Management Sciences, 2(2), 2013, pp.3-8.

24. Anukul, M., Deshmukh, S.G.,"Vendor selection Using Interpretive Structural Modeling (ISM)", International Journal of Operations and Production Management, 14(6), 1994, pp. 52-59.

25. C.L. Hii, C.L. Law, M. Cloke, "Modelling of thin layer drying kinetics of cocoa beans during artificial and natural drying", Journal of Engineering Science and Technology, 3(1), 2008, pp. 1-10.

26. Lasisi, "A comparative study of effects of drying methods on quality of cocoa beans", International Journal of Engineering Research and Technology, 3(1), 2014, pp. 991-99.

27. Guehi,S.,T., Irie, Zahouli, B., Koffi, B.,L., F.,A., Monke, Fae,. A, Nemlin, "Performance of different drying methods and their effects on the chemical quality attributes of raw cocoa material", International Journal of Food Science and Technology, (45), 2010, pp. 1564-1571.

28. Sulaiman, B.K., Ibrahim, W.A.W. and Yang, A.T., "Effect of fermentation duration using shallow box on $\mathrm{Ph}$, equivalent percent fully brown and flavour attributes of Malaysian cocoa beans", Journal of Applied Science and Agriculture, 9(11), 2014, pp. 104108.

29. Karadeniz, M., "The Importance of customer based strategic brand equity management for enterprises", Journal of Naval Science and Engineering, 6 (2), pp. 117-132.

30. Gilaninia S., Ganjinia , H., Moradi S., "Overview on importance of product packing and its impact on consumer purchasing process", International Journal of Business and Behavioral Sciences, 3(8), 2013, pp.50-54.

31. Suchanek, P., Richter, J. and Kralova, M., "Customer satisfaction, product quality and performance of companies", Review Of Economic Perspectives 14(4), 2014, pp. 329-344.

32. Fitriani., Sarono., \& Widodo. Y. R. The level of adoption of the corn-based food diversification society organizations in Lampung province', Journal Agribisnis Politeknik Negeri Lampung, 24(1), 2011, pp.68-73.

33. Monsef, S., Ismail W. K., "The Impact of open innovation in new product development process", International Journals Fundamental Psychology and Social Science, 2(1), 2012, pp.7-12.

34. Ibidunni S.O., Iyiola O., "Product Innovation, A Survival strategy For Small And Medium Enterprises In Nigeria", European Scientific Journal, 10(1), 2014, pp. 194-209. 